*Proceedings*

\title{
A New Textile Economy: Synthesis and Characterization of Phenolic Type Resin with Protein from Waste Textiles Suitable for Wood-Based Panels $+$
}

\author{
Evangelia Tarani 1, Dimitra Patsiaoura 1, Electra Papadopoulou 2, Eleni Pavlidou 1, and \\ Konstantinos Chrissafis ${ }^{1, *}$
}

1 Laboratory of Advanced Materials \& Devices, Physics Department, Aristotle University of Thessaloniki, GR 54124, Thessaloniki, Greece; etarani@physics.auth.gr (E.T.); dpatsi@physics.auth.gr (D.P.); elpavlid@auth.gr (E.P.); hrisafis@physics.auth.gr (K.C.)

2 CHIMAR HELLAS S.A., 15 km National road Thessaloniki-Polygyros, P.O. Box 60666, GR 57001, Thessaloniki, Greece; Papadopoulou@ari.gr

* Correspondence: hrisafis@physics.auth.gr; Tel.: +30-2310-99-8188 (K.C.)

+ Presented at the First International Conference on "Green" Polymer Materials 2020, 5-25 November 2020; Available online: https://cgpm2020.sciforum.net/.

Published: 4 November 2020

\begin{abstract}
The population growth and the limited reservoir of fossil resources have ignited the attention of scientific communities and entrepreneurs to produce alternative products with rawmaterials from renewable sources. In this work, proteins derived from the recycling of waste textiles were studied as raw-material in the synthesis of thermosetting polymers of a phenolic type suitable for use as adhesives in the production of wood-based panels. The chemical bonds between rawmaterials and phenol-formaldehyde (PF) resins were verified with Fourier Transform Infrared spectroscopy. The curing performance and thermal stability of the thermosetting PF resins were studied with Differential Scanning Calorimetry and Thermogravimetric Analysis, respectively. Wood-based panels were prepared and tested at a lab scale following simulation of the industrial practice. Optical Microscope and Scanning Electron Microscopy were applied for the study of the interaction between PF resins and woodchips at the lab scale. It was found that the resins were successfully prepared. The maximum curing temperature of the experimental resins was shifted to higher values than the control PF. The protein-based resins seem to lose mass at a lower rate, which denotes that they are more thermally stable than a typical PF resin.
\end{abstract}

Keywords: PF resin; waste textiles; renewable sources; wood-based panels; curing; thermal stability

\section{Introduction}

In the woodworking industry, an essential application of adhesive is in manufacturing particleboards. The most used adhesives in the production of particleboards are the phenol formaldehyde (PF) and Urea-formaldehyde (UF) resins. PF resin presents some advantages such as fast curing, good performance in the panel, water solubility, and low price. PF resin is preferred by the wood-based panels industry due to its high reactivity and cost efficiency [1]. However, some disadvantages of PF is its dark color, expensive price, and formaldehyde emissions [2].

An ongoing effort is being made to enhance the properties of PF resin, and among others, to replace its petrochemical ingredients with renewable raw materials. Emphasis is placed on the replacement of formaldehyde by other chemicals of natural origin, or the reduction of formaldehyde emissions in PF-wood panels using bio-based additives [2,3]. Biomass belongs to the most promising candidates because it provides energy and a variety of chemical blocks appropriate for the synthesis 
of many materials. Biomass from agricultural products or residues, animal wastes, textile wastes, is broadly available worldwide.

Global population growth has contributed to an increase in the production of textiles and, subsequently, textile waste. Textile wastes, when recycled, is a major source of natural and polymeric raw materials for the chemical and textile industry, as its main components are organic fibers (cotton (cellulose) and wool) and artificial fibers [3-6]. All these factors have attracted researchers to investigate the possibility of using textile wastes for the synthesis of adhesives.

In this study, an experimental PF resin with $20 \%$ phenol replacement by proteins derived from the recycling of waste textiles was studied and compared with a typical PF resin synthesized from petrochemical raw materials. The chemical bonds were verified with Fourier Transform Infrared spectroscopy (FTIR). The curing performance and thermal stability of the thermosetting PF resins were studied by using Differential Scanning Calorimetry (DSC) and Thermogravimetric Analysis (TGA), respectively. Wood-based panels were prepared and tested at a lab-scale following simulation of the industrial practice. For the study of the PF-woodchips interaction, Optical Microscope and Scanning Electron Microscopy (SEM) were applied. This project is a new idea of a circular economy to use waste fabrics as raw materials in the chemical and textile industry.

\section{Materials \& Methods}

Both PF and PPF20 resins were kindly provided by the company CHIMAR HELLAS S.A. that produced them following a proprietary synthesis process suitable for industrial productions $[7,8]$. The experimental PF resin was synthesized by replacing $20 \%$ of the necessary phenol with proteins derived from the recycling of waste textiles (PFP20 sample name), while the typical PF resin was synthesized by using only petrochemical raw materials. Wood-based panels were prepared and tested at a lab-scale following simulation of the industrial practice.

FTIR in transmittance mode was used to study the synthesized materials. The spectra were received with a Spectrum 1000 Perkin-Elmer spectrometer in the spectral area $4000-400 \mathrm{~cm}^{-1}$, a resolution of $2 \mathrm{~cm}^{-1}$ and 32 scans. For the resins in liquid form, the sandwich preparation method was used, in which a drop of hybrid is placed between two KBr pellets of $100 \mathrm{mg}$ each. $\mathrm{KBr}$ pellets of 200 $\mathrm{mg}$ with $1 \mathrm{wt} . \%$ of the powdered material have been developed for solid samples.

TGA of the resins was carried out using a SETARAM SETSYS TG-DTA 16/18 instrument by heating the samples from 25 to $1000{ }^{\circ} \mathrm{C}$ in a $50 \mathrm{~mL} / \mathrm{min}$ flow of air atmosphere at a heating rate of $20^{\circ} \mathrm{C} / \mathrm{min}$. Samples of $10 \pm 0.5 \mathrm{mg}$ were placed in alumina crucibles, while an empty alumina crucible was used as a reference.

DSC of the resins has been performed in a DSC 141 (Setaram). Temperature and energy calibrations of the instrument were performed for different heating rates, using the well-known melting temperature and melting enthalpies of high-purity Zinc, Tin, and Indium. The DSC measurements were carried out with liquid resin in stainless steel crucibles, while an identical empty crucible was used as a reference in each measurement. The samples were heated from ambient temperature to $250{ }^{\circ} \mathrm{C}$ with a heating rate of $5{ }^{\circ} \mathrm{C} / \mathrm{min}$ in a $50 \mathrm{~mL} / \mathrm{min}$ flow of nitrogen.

The samples were examined with a ZEISS STEMI DV4 microscope and their surface was photographed with a SONY Cybershot digital camera.

SEM micrographs of the prepared samples were studied by using a SEM JEOL JSM-390LV model. The specimens were carbon coated to provide good conductivity of the electron beam and the operating conditions were accelerating voltage $20 \mathrm{kV}$, probe current $45 \mathrm{nA}$, and counting time $60 \mathrm{~s}$.

\section{Results \& Discussion}

\subsection{IR Analysis of PF Resins and PF/Woodchips Samples}

Figure 1 shows the IR spectra of the typical PF resin, experimental PFP20 resin, woodchips, and the woodchips impregnated with synthesized resins. All spectra are characterized by the presence of a broad band of $\mathrm{OH}$ stretching in the $3300 \mathrm{~cm}^{-1}$ region. Bands of the typical PF and PFP20 resins at $1680-1650 \mathrm{~cm}^{-1}, 1480-1450 \mathrm{~cm}^{-1}, 1260 \mathrm{~cm}^{-1}$, and $1060 \mathrm{~cm}^{-1}$ are assigned to $\mathrm{C}=\mathrm{O}$ stretching of a benzene 
ring, $\mathrm{CH}$ deformation in $-\mathrm{CH}_{2}$ groups, biphenyl ether $\mathrm{C}-\mathrm{O}$ stretching and dimethylene ether $\mathrm{C}-\mathrm{O}$ deformation, respectively. The band observed at $1378 \mathrm{~cm}^{-1}$ is attributed to the in-plane deformation of phenolic $\mathrm{OH}$. The bands at 1208 and $1225 \mathrm{~cm}^{-1}$ are attributed to the in-plane vibration of the C-O of the phenolic group. The bands at 1150 and $1050 \mathrm{~cm}^{-1}$ are characterized for the in-plane deformation of aromatic $\mathrm{C}-\mathrm{H}[1]$.

The samples with woodchips, beyond the characteristic peaks of the resins, show the two bands of $\mathrm{CH}$ stretching at 2900 and $2800 \mathrm{~cm}^{-1}$, and aromatic ring vibrations at the $1600-1500 \mathrm{~cm}^{-1}$. The band at $1459 \mathrm{~cm}^{-1}$ is assigned to the $\mathrm{C}-\mathrm{H}$ deformation in the $-\mathrm{CH}_{3}$ of a methoxyl group. The band at 1380 $\mathrm{cm}^{-1}$ is attributed to $\mathrm{C}-\mathrm{O}$ of a syringyl unit. The bands at $1170 \mathrm{~cm}^{-1}$ and $1042 \mathrm{~cm}^{-1}$ are assigned to the $\mathrm{C}-\mathrm{H}$ stretching in a syringyl unit and the $\mathrm{C}-\mathrm{O}$ of a primary alcohol, respectively [1].

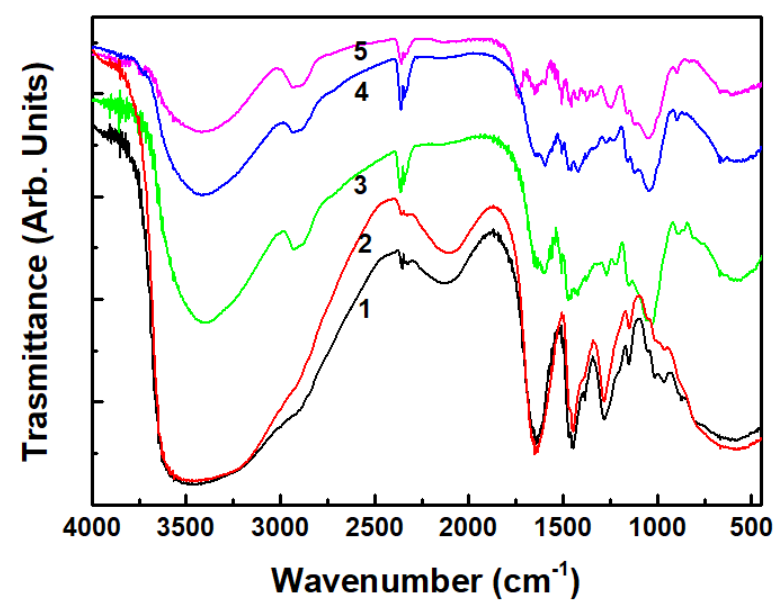

Figure 1. IR spectra of 1: PF, 2: PFP20, 3: PF/woodchips, 4: PFP20/woodchips, and 5: woodchips.

\subsection{Thermal Study of PF Resins and PF/Woodchips Samples}

Figures $2 \mathrm{a}$ and $2 \mathrm{~b}$ show the TGA graphs and the corresponding derivative plot of the mass loss versus temperature (DTG) of the typical PF, PFP20 resin, PF/woodchips, and PFP20/woodchips samples. The TGA graph of the typical PF shows that degradation is completed in three steps. The first mass loss is performed at temperatures between 30 and $260{ }^{\circ} \mathrm{C}$, where about $40 \%$ of the initial mass is lost due to the loss of water and small molecules like free formaldehyde and further crosslinking and loss of byproducts [7,9]. A further $10 \%$ of the mass is lost at the temperature range of $290-579{ }^{\circ} \mathrm{C}$, where the pyrolytic degradation of polymers takes place. At $450{ }^{\circ} \mathrm{C}$, the decomposition of aromatic rings takes place [10]. The DTG graph in Figure $2 \mathrm{~b}$ shows the mass reductions by two endothermic curves at $136^{\circ} \mathrm{C}$ and $465{ }^{\circ} \mathrm{C}$. The above findings are consistent with literature references [7]. The TGA analysis of the PFP20 resin indicates an initial mass loss from 30 to $260{ }^{\circ} \mathrm{C}$, which is attributed to the loss of the water content and emission of the unbounded formaldehyde in the resin. There is a mass loss of about $8 \%$ at $300-560^{\circ} \mathrm{C}$ due to the breakdown of methylene linkages to produce aldehydes and phenols [7]. Finally, about $7.5 \%$ of the mass remains.

Woodchips were also subjected to TGA to investigate the decomposition and the highest temperature that can be safely applied during the production of the wood-based panels. The first mass reduction in the TGA plot is attributed to the water-humidity loss of the chips that occur close to $100{ }^{\circ} \mathrm{C}$. The major mass loss of woodchips appears at $200-390{ }^{\circ} \mathrm{C}$ because of various organic compounds and wood degradation [7]. The TGA analysis of the PF/woodchips and PFP20/woodchips samples reveals a first mass loss up to the temperature of $170{ }^{\circ} \mathrm{C}$. Above this temperature, the mass of the samples decreases. The mass degradation is ended at the same temperature for both resins. However, the PFP20/woodchips sample results in higher solid residue compared to PF/woodchips. 


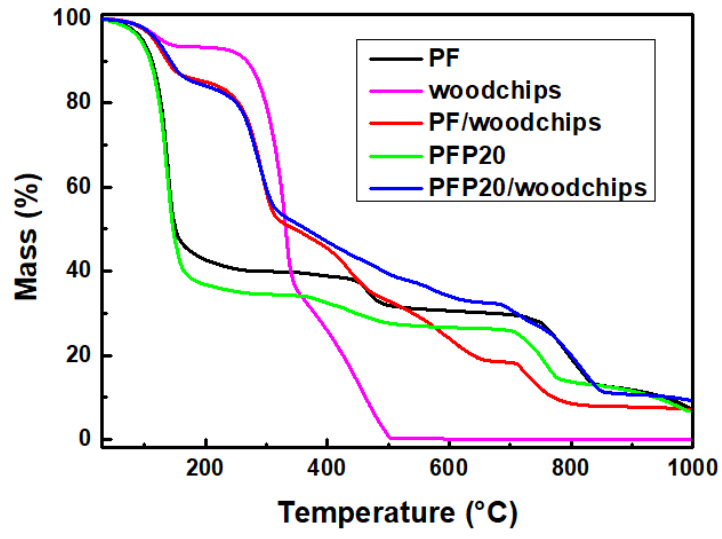

(a)

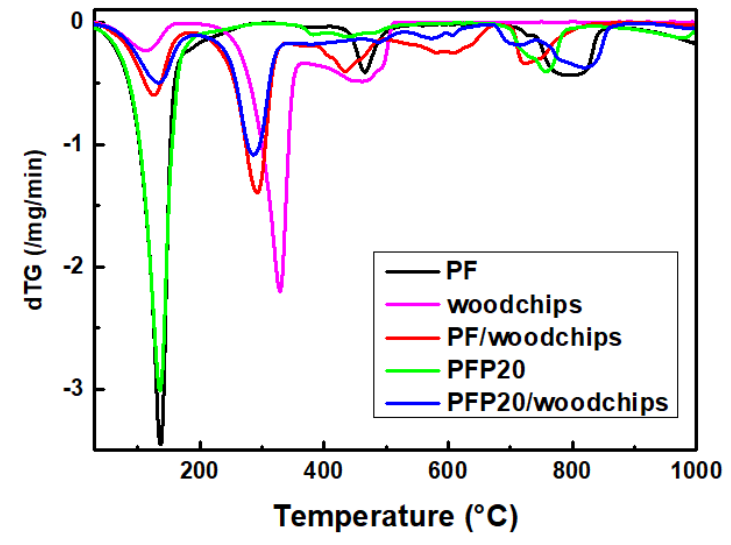

(b)

Figure 2. (a) Mass (\%) and (b) DTG versus temperature of the typical PF, woodchips, PF/woodchips, PFP20 resin, and PFP20/woodchips.

The DSC thermographs of the typical PF, experimental PFP20 resin, PF/woodchips, and PFP20/woodchips are shown in Figure 3. The typical PF and the PFP20 resin exhibit an exothermic curve with a peak at the temperature of 145.5 and $159.8^{\circ} \mathrm{C}$, respectively. According to the literature [7], both peaks occur because of the reactions of chain building condensations. The PF/woodchips and PFP20/woodchips samples show similar exothermic curves but shifted to lower temperatures (109 and $113^{\circ} \mathrm{C}$, respectively) compared to PF and PFP20 resins because of the ability of wood to accelerate the curing of the adhesives [7]. Nevertheless, the DSC graph of wood impregnated with PFP20 resin shows a significant reduction of peak temperature, the curing performance is still higher than that of the typical PF resin.

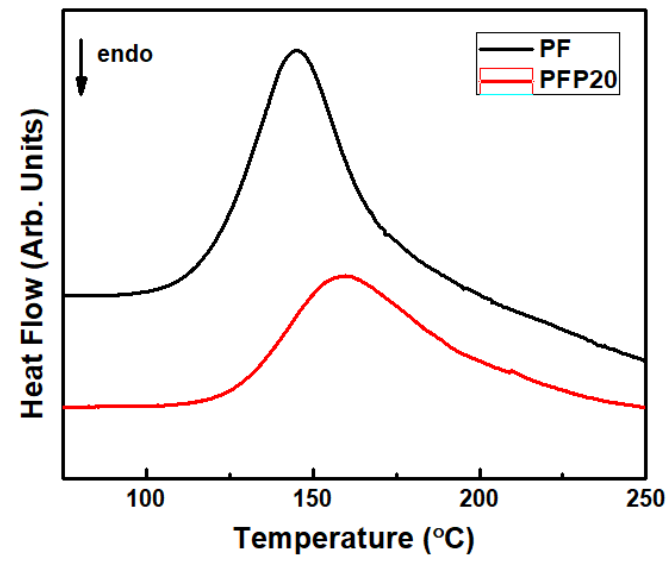

(a)

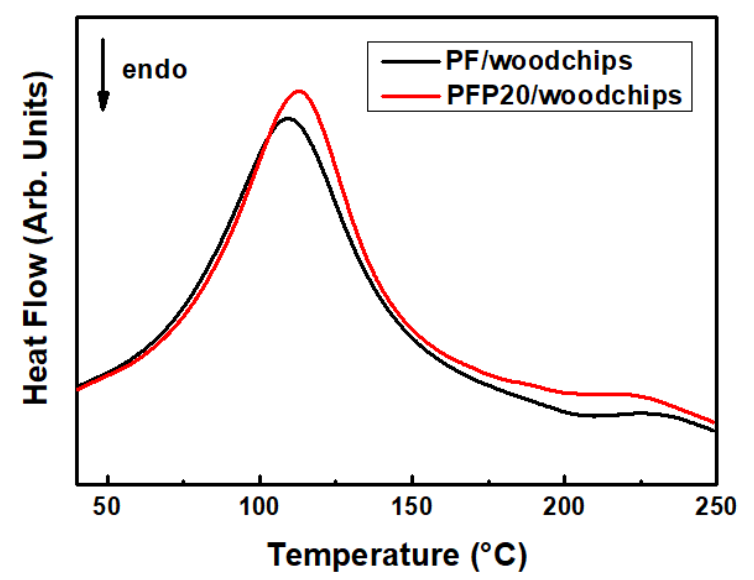

(b)

Figure 3. HeatFlow versus temperature of (a) typical PF and PFP20 resin and (b) PF/woodchips and PFP20/woodchips.

\subsection{Morphological Characterization of PF/Woodchips Samples}

Figures 4a-4f show the Optical Microscope Images of resin-wood composites (PF/woodchips and PFP20/woodchips). It was found that the woodchips are completely covered by the resins. However, the coverage is not uniform across its surface. Figures 4.a and 4.a show the resin-saturated regions and the formation of resinous deposits, whose presence has also been identified during SEM observation (see below). Figures $4 \mathrm{c}$ and $4 \mathrm{~d}$. show the cross-section Optical Microscope of $\mathrm{PF} /$ woodchips and PFP20/woodchips samples, respectively. The grinding process on the surface of the resin/wood composite was performed using sandpaper. It was impossible to estimate the 
penetration depth of resins into the wood due to the limited resolution of the Optical Microscope. However, Figures $4 \mathrm{c}$ and $4 \mathrm{~d}$. confirm the resin's penetration into the wood structure, although many different fragments of wood and resin disrupt the Optical Microscope analysis.

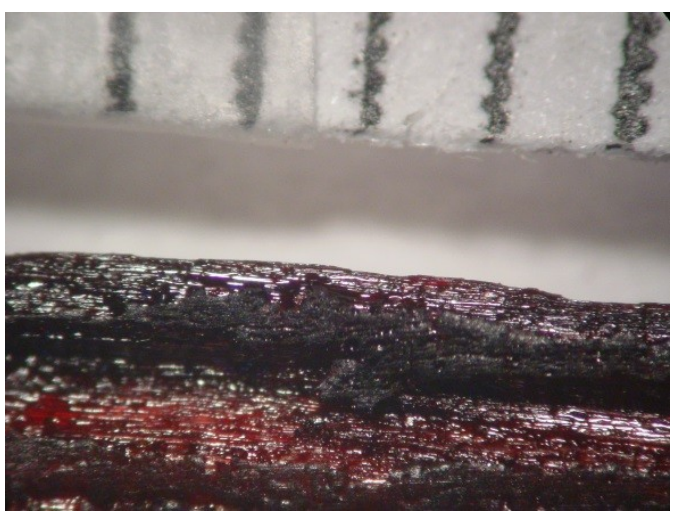

(a)

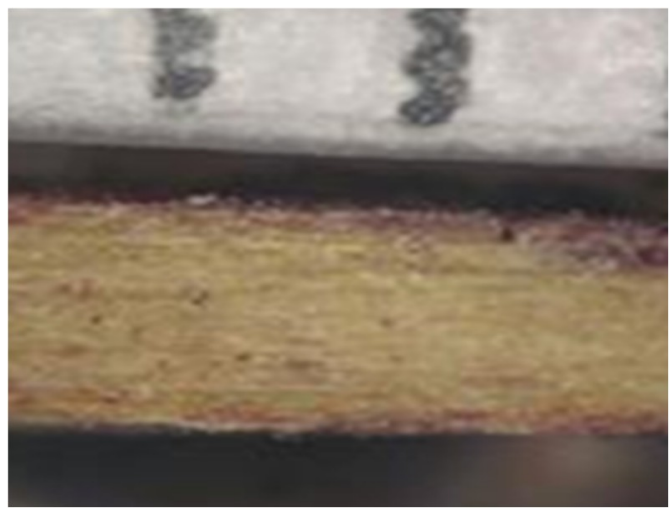

(c)

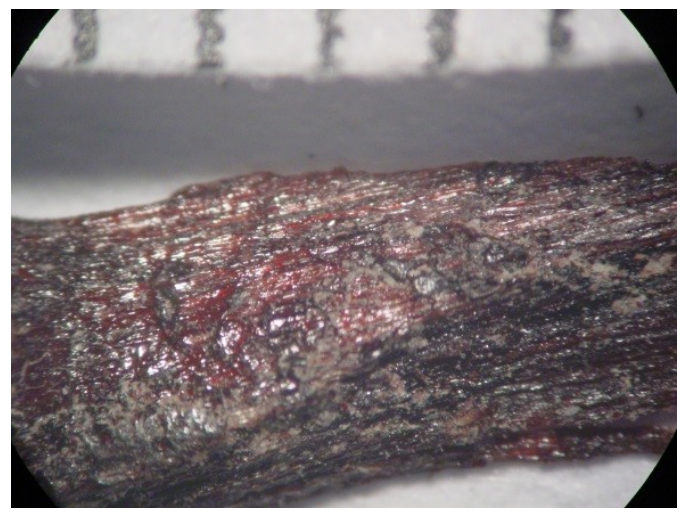

(b)

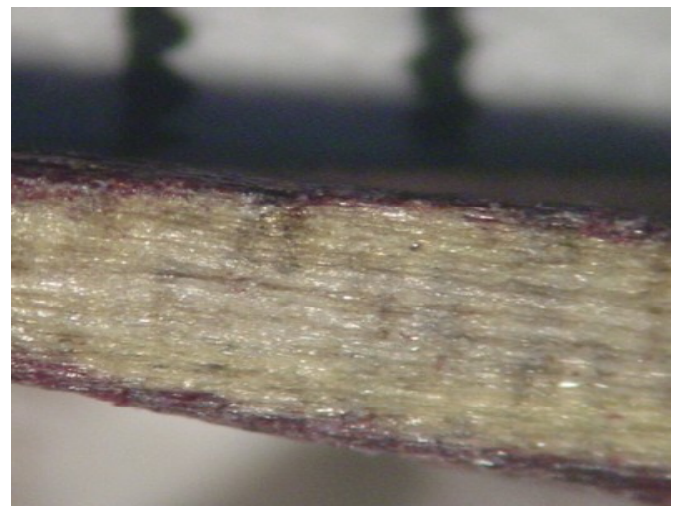

(d)

Figure 4. Optical Microscope images of (a), (c) control PF, and (b), (d) PFP20 resin.

Figures 5a-5d show the morphology of the resin/wood composites of the two resins used in this study (PF/woodchips and PFP20/woodchips). It was found that the woodchips are completely covered by the resins (SEM Images of PF/woodchips sample in Figures 5a, 5c, and SEM images of PFP20/woodchips sample in Figures 5b, 5d). So, the typical PF resin completely covers the wood without allowing any observation of the porous structure of the wood. On the contrary, the PFP20 resin allows the observation of the microstructure of the wood demonstrating the successful penetration of the resin on the wood surface.

Figures 6a-6c show the SEM Images of PFP20/woodchips sample obtained by grinding the surface of samples with sandpaper. As already mentioned, it is not possible to estimate the penetration depth of the resin into the woodchips due to the presence of many different fragments of resin and wood and to the organic nature of the two materials as well. Therefore, since the resinwood distinction cannot be achieved, a comparative morphological study is performed between the two regions of the same sample. In Figure 6a, the middle area of the PFP20/woodchips composite in which the resin cannot penetrate is given in a yellow frame, while the green frame gives the area near the edges of the sample. The longitudinal lines running through the sample surface are due to the grinding process. Figures 6.b and 6.c show that the morphology of the two different points is different. Consequently, in the middle area (yellow), a "purer" sample morphology was observed compared to the edges of the PFP20/woodchips composite (green). This confirms the presence of the resin near the edges of the cross-sectioned sample. Also, in this case, the penetration depth of resin into the wood cannot be estimated. 


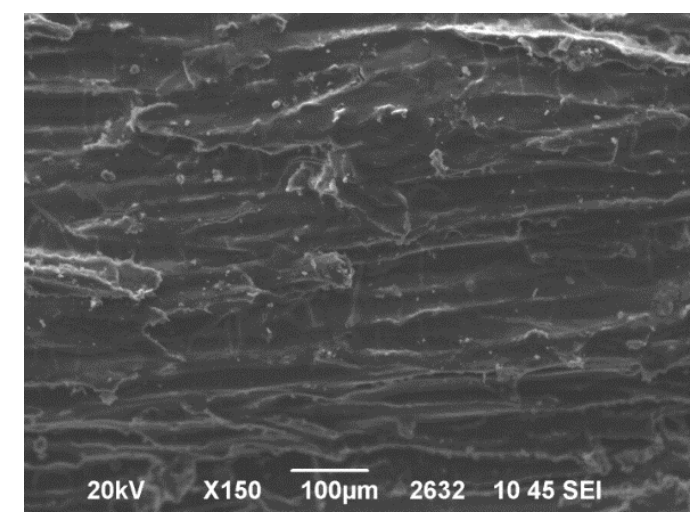

(a)

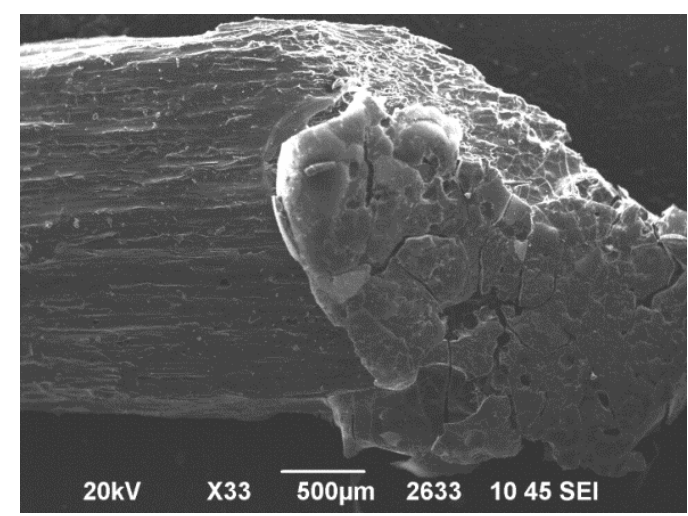

(c)

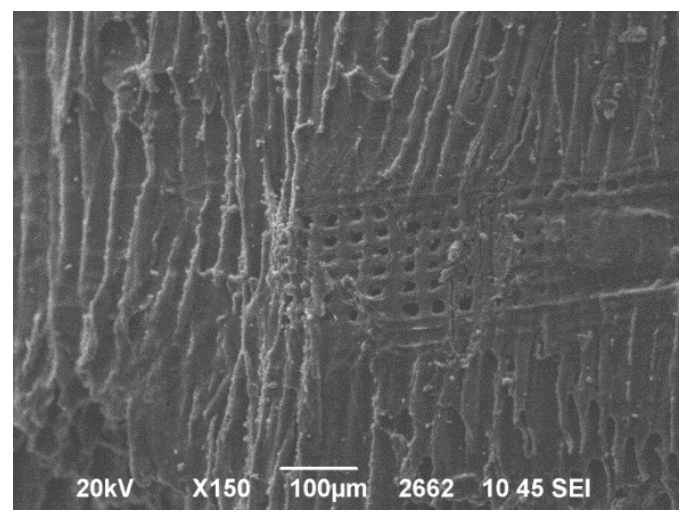

(b)

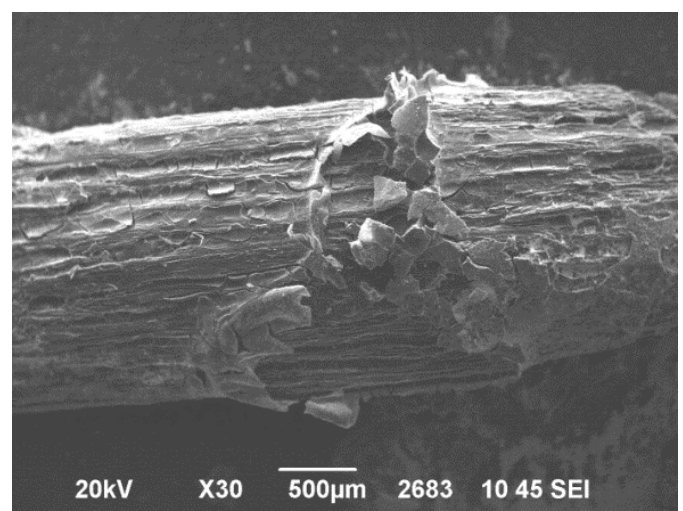

(d)

Figure 5. SEM images of (a), (c) typical PF, and (b), (d) PFP20 resin.

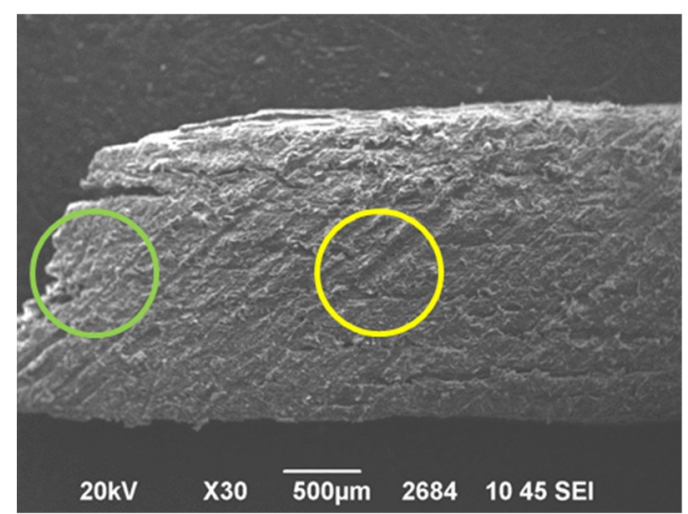

(a) 


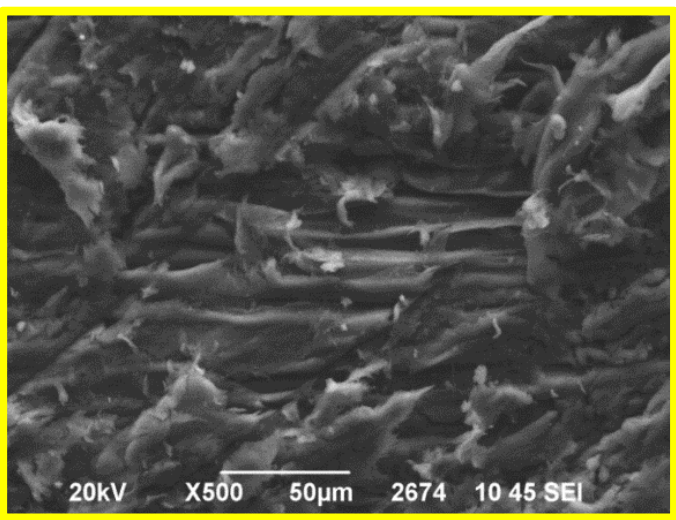

(b)

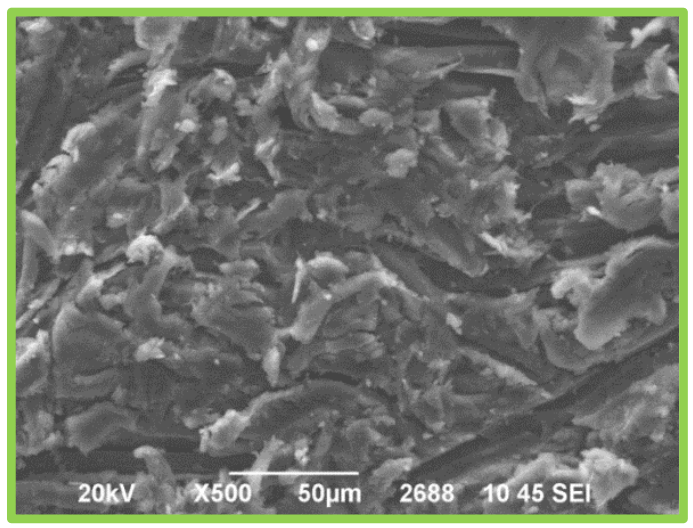

(c)

Figure 6. Cross-section SEM images of (a) PFP20/woodchips in (b) the middle (yellow) and (c) at the edge (green) of the sample.

\section{Conclusions}

In this work, the standard PF and PFP20 resins were found to have been prepared successfully. According to the IR analysis, the resins blended with woodchips, beyond the characteristic peaks of the resins, show peaks of the functional groups of woodchips. The mass degradation of the woodchips impregnated with resins is ended at the same temperature with the PFP20/woodchips sample to present higher solid residue compared to PF/woodchips. Additionally, although the PFP20 resin cures at a higher temperature than the typical PF resin, it has been shown that the PFP20/woodchips composite decreases the curing efficiency. Optical Microscope analysis and SEM micrographs confirm the resin's penetration into the wood structure with the PFP20 resin to allow the observation of the porous structure of the wood. We conclude that a PF resin with up to $20 \%$ phenol replacement by textile wastes can be considered competitive in the production of particleboards with a typical PF resin because it enables the partial replacement of phenol by a natural material supporting the sustainability of our ecosystem without coming behind in the performance and properties of the plywood panels.

Acknowledgments: This research was carried out within the project "A new circular economy concept: from textile waste towards chemical and textile industries feedstock-RESYNTEX" that was funded by the European Union's Horizon 2020 research and innovation programme under grant agreement No 641942.

Author Contributions: Conceptualization, K.C.; methodology, E.T, D.P. and E.S.P.; formal analysis, E.T and D.P.; investigation, E.T, D.P., and E.S.P.; writing - original draft preparation, E.T.; writing-review and editing, E.T, D.P., E.S.P., E.G.P., and K.C.; supervision, K.C.

Conflicts of Interest: The authors declare no conflict of interest.

\section{Abbreviations}

The following abbreviations are used in this manuscript:

PF: Phenol-Formaldehyde

PFP20: PF resin synthesized by replacing $20 \%$ of the phenol by proteins derived by textile wastes

UF: Urea-formaldehyde

DSC: Differential Scanning Calorimetry

TGA: Thermogravimetric Analysis

DTG: Derivative of mass

FTIR: Fourier Transform Infrared Spectroscopy

SEM: Scanning Electron Microscopy 


\section{References}

1. Khan, M.A.; Ashraf, S.M.; Malhotra, V.P. Eucalyptus bark lignin substituted phenol formaldehyde adhesives: A study on optimization of reaction parameters and characterization. J. Appl. Polym. Sci. 2004, 92, 3514-3523.

2. Nemli, G.; Odabaş-Serin, Z.; Özdemir, F.; Ayrılmış, N. Textile dust for particleboard. BioResources 2019, 14, 120-127.

3. Zonatti, W.F.; Guimarães, B.M.G.; Duleba, W.; Ramos, J.B. Thermoset composites reinforced with recycled cotton textile residues. Text. Cloth. Sustain. 2015, 1, 1-12.

4. Temmink, R.; Baghaei, B.; Skrifvars, M. Development of biocomposites from denim waste and thermoset bio-resins for structural applications. Compos. Part A Appl. Sci. Manuf. 2018, 106, 59-69.

5. Wanassi, B.; Hariz, I. Ben; Ghimbeu, C.M.; Vaulot, C.; Jeguirim, M. Green carbon composite-derived polymer resin and waste cotton fibers for the removal of alizarin red S dye. Energies 2017, 10.

6. Qu, J.; Wang, Z.; Hu, C.; Yin, Q.; Pang, Y. Potential use of waste cotton in production of biomass composites. BioResources 2019, 14, 8424-8438.

7. Papadopoulou, E.; Chrissafis, K. Thermal study of phenol-formaldehyde resin modified with cashew nut shell liquid. Thermochim. Acta 2011, 512, 105-109.

8. Papadopoulou, E.; Kountouras, S.; Nikolaidou, Z.; Chrissafis, K.; Michailof, C.; Kalogiannis, K.; Lappas, A.A. Urea-formaldehyde (UF) resins prepared by means of the aqueous phase of the catalytic pyrolysis of European beech wood. COST Action FP1105. Holzforschung 2016, 70, 1139-1145.

9. Papadopoulou, E.; de Wild, P.J.; Kountouras, S.; Chrissafis, K. Evaluation of torrefaction condensates as phenol substitutes in the synthesis of phenol-formaldehyde adhesives suitable for plywood. Thermochim. Acta 2018, 663, 27-33.

10. Papadopoulou, E.; Kountouras, S.; Chrissafis, K.; Kirpluks, M.; Cabulis, U.; Švíglerová, P.; BenjellounMlayah, B. Evaluation of the particle size of organosolv Lignin in the synthesis of resol resins for plywood and their performance on fire spreading. Tappi J. 2017, 16, 409-416.

(C) 2020 by the authors. Submitted for possible open access publication under the terms and conditions of the Creative Commons Attribution (CC BY) license (http://creativecommons.org/licenses/by/4.0/). 